\title{
Integração de políticas públicas no Brasil: o caso dos setores de recursos hídricos, urbano e saneamento
}

\author{
Integrating public policies in Brazil: \\ the case of water resources, urban and sanitation sectors
}

Ester Luiz de Araújo Grangeiro [I]

Márcia Maria Rios Ribeiro [II]

Lívia Izabel Bezerra de Miranda [III]

\section{Resumo}

Este artigo analisa como as políticas urbanas e de recursos hídricos foram formuladas e implementadas no Brasil até janeiro de 2019, as descontinuidades e quais as possibilidades de integração entre elas, com vistas a potencializar um modelo de gestão adequado aos processos do ciclo hidrológico e da dinâmica urbana. Foi percebido que, embora no Brasil existam legislações avançadas, ainda há lacunas que dificultam a articulação da gestão das águas com o território, pois suas políticas foram pensadas e implementadas como se as dinâmicas fossem independentes. Portanto, foi sugerida uma proposta de articulação que destaca a aproximação dos atores envolvidos através dos espaços participativos, nos quais tanto o poder público quanto a sociedade se apropriam das questões inerentes à gestão.

Palavras-chave: cidades; abordagem participativa; gestão ambiental; recursos hídricos; saneamento.

\begin{abstract}
This article analyzed how public policies focusing on urban and water resources management were formulated and implemented in Brazil up to January 2019, as well as the discontinuities and possibilities of integration between them, in order to enhance a management model suitable to the processes of the hydrologic cycle and urban dynamics. We noticed that, in spite of the advanced laws that exist in Brazil, some gaps must be overcome for a better articulation between territory and water management, as policies were made and implemented as if their dynamics were independent. Therefore, we suggest an articulation proposal that highlights the interaction of the actors involved through participatory spaces, where both government and society take responsibility for the issues inherent in management.
\end{abstract}

Keywords: cities, participatory approach, environmental management, water resources, sanitation. 


\section{Introdução}

As transformações ocorridas nas cidades, sobretudo diante do rápido processo de urbanização que se apresenta como um importante desafio para o planeta (Mitchell, Enemarkb e Van Der Molen, 2015), geram uma grande pressão sobre os recursos hídricos, agravada pelos efeitos das mudanças climáticas globais (Barron et al., 2017).

Em muitos casos, associado ao processo de urbanização, surgem problemas sociais que são resultado da incapacidade de se planejar e gerir a urbanização em âmbito nacional, estadual e municipal (Peixoto, Studart e Campos, 2016). Nesses casos, é necessária uma adequada integração entre a água e o planejamento do uso do solo, tanto para permitir que os sistemas urbanos continuem a existir quanto para reduzir o impacto nos recursos hídricos em escala regional (Serrao-Neumann et al., 2017).

Outro desafio para a integração da gestão urbana e dos recursos hídricos é o fato da água estar ligada de maneira transversal a múltiplos setores, lugares e pessoas e, também, a escalas geográficas e temporais distintas (OECD, 2015). Mas, na maioria dos casos, as fronteiras hidrográficas e os perímetros administrativos municipais não coincidem.

O conceito de integração de políticas ambientais, apresentado por Runhaar, Driessen e Uittenbroek (2014), surge como uma alternativa à gestão fragmentada e com setores desconectados, pois a EPI (EPI, do inglês - Environmental policy integration) aborda as preocupações ambientais nas políticas de agricultura, urbana, transportes, entre outras. Essa abordagem evidencia a necessidade de integração das questões ambientais nos níveis mais altos de tomada de decisão (Browne e Rutherfurd, 2017).

Sendo as políticas públicas um conjunto de ações dos governos que tem reflexos na vida dos cidadãos (Souza, 2006), a formulação, integração e implementação dessas políticas devem buscar amenizar e solucionar questões que comprometem a qualidade de vida das pessoas. A integração de políticas gera benefícios mútuos aos setores envolvidos, pois as ações desenvolvidas no âmbito de uma política setorial têm potencial de influenciar diretamente outro setor (Runhaar, Driessen e Uittenbroek, 2014).

No Brasil, a gestão dos recursos hídricos é de domínio da União e dos Estados, conforme a Constituição Federal de 1988, mas influencia diretamente a qualidade de vida urbana, visto que os serviços de saneamento básico deficientes podem comprometer a salubridade ambiental e a vida humana.

Já a gestão urbana é de competência do município e deve ser realizada em nível de território municipal. No âmbito da gestão urbana, estão o planejamento do uso do solo, a mobilidade urbana, a habitação e o saneamento.

No entanto, é importante notar que a gestão do saneamento é diretamente influenciada pela gestão dos recursos hídricos na bacia hidrográfica. E que, embora as ações municipais sobre os recursos hídricos, encontrem-se voltadas prioritariamente para medidas de saneamento básico (Tonella, 2013), elas se limitam aos input/output na bacia hidrográfica, ignorando seus fluxos. 
Na contramão dessa forma de gestão, Wong (2017) aborda o conceito de Planejamento Urbano Sensível aos Recursos Hídricos (WSUD), segundo o qual a integração do planejamento urbano com ciclo das águas urbanas tem como objetivo garantir que o gerenciamento das águas urbanas seja sensível aos processos hidrológicos e ecológicos naturais.

No WSUD, a integração não se limita a medidas de saneamento, mas tem como objetivos principais a conservação da água potável, a minimização na geração de esgotos e o gerenciamento da quantidade e qualidade das águas pluviais.

No Brasil, a completa integração entre a gestão dos recursos hídricos e a gestão urbana ainda é um desafio, embora a legislação sinalize para sua necessidade. É fato que muitos problemas de gestão de recursos surgem a partir de falhas na governança, assim uma melhor compreensão sobre governança é essencial para a gestão dos recursos naturais, entre eles os recursos hídricos (Knieper et al., 2010).

Nesse contexto, o conceito de governança da água surge como uma possibilidade interessante no âmbito do WSUD. A governança da água pode ser entendida, de modo geral, como os atores sociais e os agentes governamentais responsáveis por uma boa gestão da água, assim como instituições, regras e procedimentos para tomada de decisão (Campos e Fracalanza, 2010).

Alves (2018) conceitua a governança como algo mais amplo que governo, pois envolve maior gama de agentes, não necessariamente apenas os políticos, como no sistema público. Segundo a autora, a governança é um aspecto característico da descentralização política no Brasil, visando a favorecer a interação entre setor público e sociedade na busca por maior eficiência nas ações.

Nesse contexto, este artigo analisa como as políticas urbanas e de recursos hídricos foram formuladas e implementadas no Brasil até janeiro de 2019, suas descontinuidades e quais as possibilidades de integração entre elas, com vistas a potencializar um modelo de gestão adequado aos processos do ciclo hidrológico e da dinâmica urbana.

Cabe destacar que este artigo é parte de pesquisa de doutorado no qual serão investigados aspectos sobre a governança da água, analisando as interfaces da gestão dos recursos hídricos, entre elas a gestão urbana. A pesquisa pretende sugerir diretrizes para promover o fortalecimento institucional, como a minimização dos impactos negativos do modelo atual nos sistemas de recursos hídricos.

\section{Metodologia}

Na perspectiva de investigar a construção das políticas urbanas e de recursos hídricos e como estas foram estruturadas e consideraram a integração do território municipal e da bacia hidrográfica, as etapas metodológicas deste trabalho partiram da análise das políticas de recursos hídricos e urbana, suas estruturas legais e institucionais, análise dos avanços e entraves na articulação das políticas e, ao final, foi proposto um modelo preliminar das possibilidades de integração da gestão urbana e dos recursos hídricos.

A metodologia baseia-se na premissa de que o município (atores e instituições) 
é um ente fundamental na gestão dos recursos hídricos. Ela foi estruturada, conforme apresentada na Figura 1, em: 1) diagnóstico da gestão dos recursos hídricos no Brasil; 2) diagnóstico da gestão urbana no Brasil; 3) diagnóstico da gestão do setor de saneamento no Brasil; 4) diagnóstico das articulações existentes entre a gestão urbana e dos recursos hídricos no Brasil; e 5) proposição de um modelo preliminar de integração entre as gestões urbana e dos recursos hídricos.

\section{Resultados e discussões}

Diante da identificação de legislações avançadas no Brasil, como a política de recursos hídricos, mas também de lacunas que dificultam a articulação da gestão das águas com o território, devido a construção e implementação de políticas públicas como se as dinâmicas das águas e do território fossem independentes, os resultados e discussões deste artigo estão focados nos principais entraves e avanços que ocorreram ao longo da história, na desarticulação das políticas urbana e de recursos hídricos, com base na revisão de literatura realizada e nos documentos analisados.

\section{Política Nacional de Recursos Hídricos}

Em 1934, foi estabelecido o primeiro grande marco legislativo da gestão das águas no Brasil, o decreto n. 24.643/1934, conhecido como Código das Águas. Embora tenha sido instituído em um cenário de centralização

Figura 1 - Diagrama esquemático da metodologia do trabalho

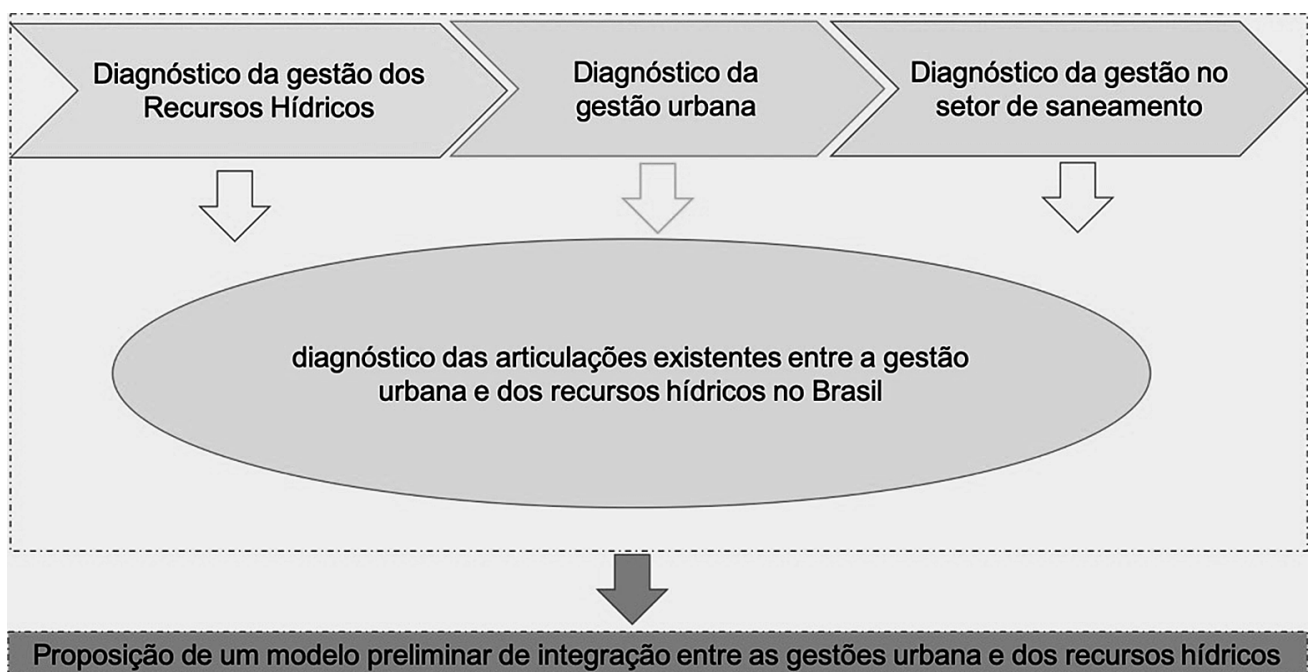

Fonte: elaborado pela autora, em 2019. 
administrativa, fortalecimento do poder central e nacionalismo (Murtha, Castro e Heller, 2015), o uso das águas era assegurado de forma gratuita para as necessidades humanas, mas eram admitidas águas de domínio público e privado.

A propriedade privada das águas foi mantida até 1988 , com a promulgação da Constituição Federal, que dividiu o domínio das águas entre a União e os estados. A Constituição vigente determinou, também, ser de competência da União instituir o Sistema Nacional de Gerenciamento de Recursos Hídricos (Singreh), bem como definir critérios de outorga de direito de uso dos recursos hídricos (inciso XIX, artigo 21).

A Lei das Águas aprovada em 1997, que instituiu a Política Nacional de Recursos Hídricos, promoveu mudanças nos aspectos administrativos, jurídicos e institucionais dos recursos hídricos no Brasil (Veiga e Magrini, 2013), e a definição da bacia hidrográfica como unidade territorial para implementação da política reflete a compreensão da complexidade dos processos ambientais (Peres e Silva , 2013).

Para colocar em prática os princípios determinados pela Lei das Águas e garantir a descentralização e a participação social, o Singreh (Figura 2) é dotado de um conjunto de instâncias decisórias composto de um colegiado deliberativo superior, formado pelo Conselho Nacional dos Recursos Hídricos (CNRH) e por seus correspondentes nos estados, os Conselhos Estaduais de Recursos Hídricos (CERH); a Secretaria de Recursos Hídricos e Qualidade Ambiental (SRHQA), que exerce a função de secretaria-executiva

Figura 2 - Sistema nacional de gerenciamento de recursos hídricos

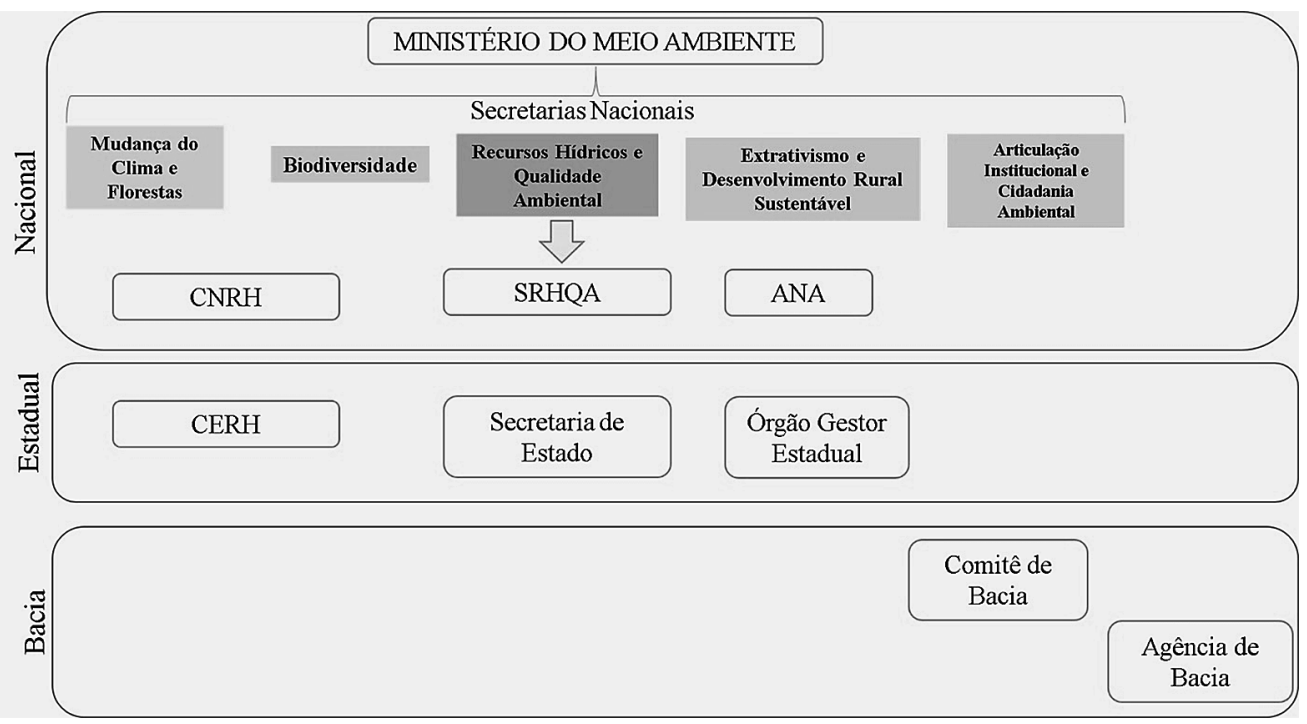

Fonte: elaborado a partir de Brasil (1997 e 2017). 
do $\mathrm{CNRH}$; órgãos colegiados regionais deliberativos instalados nas unidades de planejamento e gestão, os comitês de bacias hidrográficas de rios federais e rios estaduais; e instâncias executivas das decisões dos colegiados regionais, as Agências de Água de âmbito federal (ANA) e estadual.

A formulação e aprovação da PNRH e do Singreh ocorreram em um período em que o Brasil produzia legislação e políticas públicas que buscavam, gradativamente, consolidar uma forma de valorização de seus recursos hídricos (Ferreira, Silva e Pinheiro, 2008). Além da PNRH, nos anos 2000 , outras leis que tratavam das questões ambientais no meio urbano foram aprovadas, como a Política Nacional de Saneamento Básico (2007) e Política Nacional de Resíduos Sólidos (2010), assim como para regular as atividades no âmbito das cidades, como o Estatuto das Cidades (2001).

Embora tenham sido aprovadas tais legislações, o meio ambiente, o uso e ocupação do solo e os recursos hídricos ainda não são compreendidos como elementos do mesmo espaço (Peixoto, Studart e Campos, 2016), sobretudo pelos agentes responsáveis pela efetivação dessas políticas.

No âmbito da PNRH, por exemplo, o município aparece como parte integrante dos representantes do poder público nos comitês de bacia. No entanto, apenas parte dos municípios poderá participar do comitê de bacia hidrográfica, pois a quantidade de representantes do poder público municipal poderá ser menor que o número de municípios pertencentes à bacia hidrográfica.

Ainda que o município e a bacia hidrográfica apresentem escalas diferentes, as decisões acerca do território deveriam ser tomadas em conjunto, uma vez que a dinâmica urbana influencia consideravelmente os recursos hídricos de uma região.

\section{Política urbana}

Umas das primeiras tentativas de formulação de uma política urbana no Brasil foi o Plano Decenal (1967) que pouco avançou no sentido de formular diretrizes para uma política espacial nacional (Monte-Mór, 2007), pois apesar do documento oferecer as bases de uma política urbana nacional, se limitou ao planejamento local.

No processo de redemocratização do Brasil, na década de 1980 , surgiram duas tendências opostas de planejamento territorial: 1) uma ancorada em valores democráticos, que valorizavam a participação nas políticas públicas; e outra 2) associava as tendências globalizadas de planejamento aos conceitos de valorização do território e à eficiência dos processos de urbanização para responder às demandas do capital imobiliário.

Com a promulgação da nova Constituição Federal (1988), a política urbana foi incorporada nos artigos 182 e 183. E, após mais de uma década de discussões sobre as bases de uma política urbana, foi instituída a lei n. 10.257/2001 (Estatuto da Cidade) que estabeleceu diretrizes gerais da política urbana.

Para tratar das questões urbanas, em 2003, foi criado o ministério das cidades, e o governo federal convocou a população brasileira para elaboração de propostas sobre diversos temas (Carvalho e Moraes, 2016), entre eles o processo de construção da 
Política Nacional de Desenvolvimento Urbano (PNDU) e do Sistema Nacional de Desenvolvimento Urbano (SNDU).

No entanto, a proposta de lei para PNDU ainda não foi aprovada pelos órgãos competentes, mas o Sistema Nacional de Desenvolvimento Urbano (Figura 3) está em funcionamento.

O SNDU é composto pelo ministério das cidades e quatro secretarias nacionais (Habitação, Saneamento, Mobilidade Urbana e Desenvolvimento Urbano) assim como por um colegiado consultivo e deliberativo, o ConCidades (Conselho Nacional das Cidades) e seus correspondentes nos estados e municípios, os conselhos estaduais e municipais das cidades; as instâncias colegiadas de âmbito federal, estadual e municipal, a conferência nacional, estadual e municipal das cidades que elege os conselheiros do ConCidades; e o conselho gestor do Fundo Nacional de Habitação (CGFNH), ligado à Secretaria de Habitação.

O SNDU, diferentemente do Singreh, é setorialmente fragmentado, e cada instância tem sua própria política aprovada

Figura 3 - Sistema Nacional de Desenvolvimento Urbano

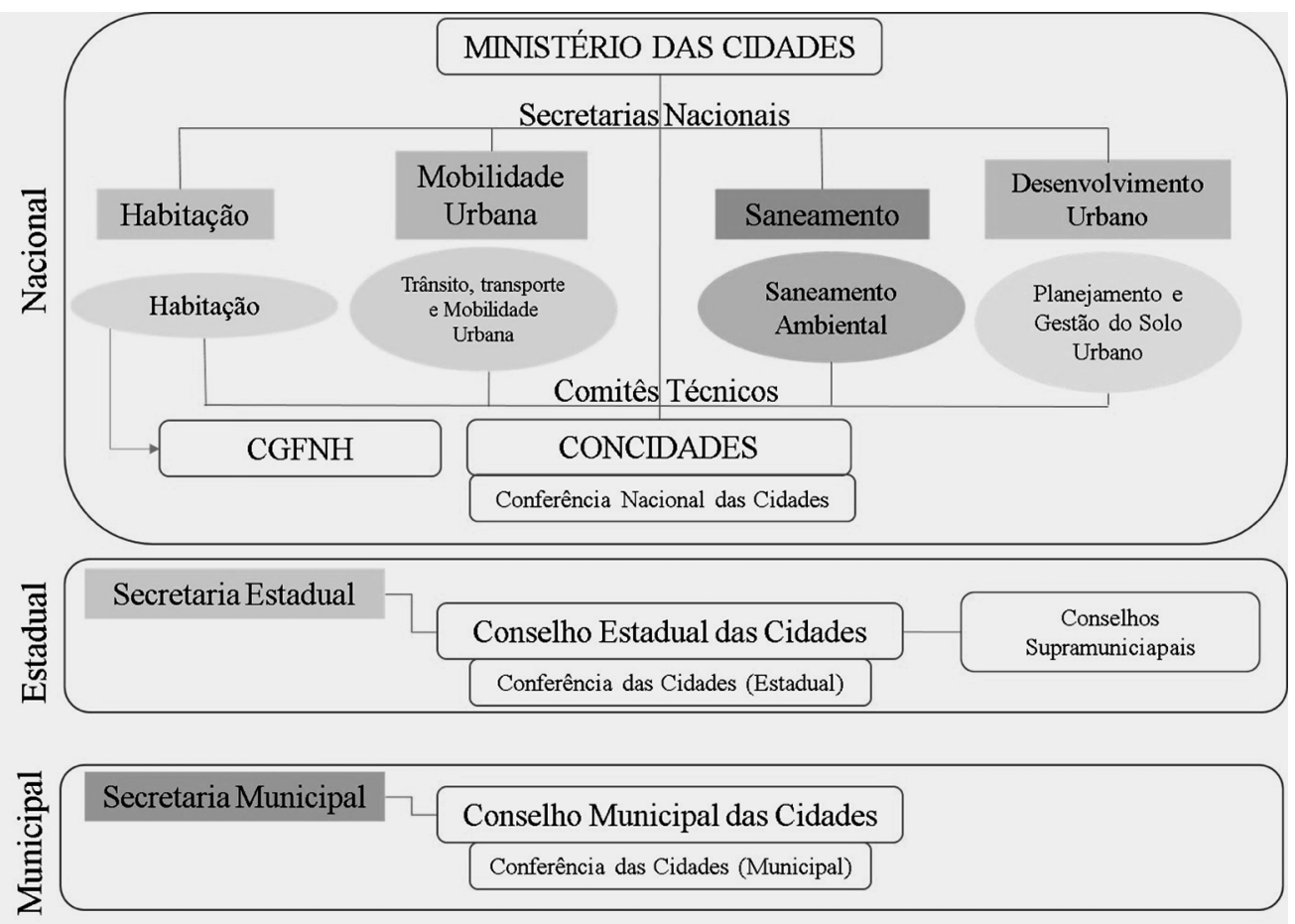

Fonte: elaborado a partir de Brasil (2017). 
em diferentes períodos, entre elas a Política Federal de Saneamento Básico (lei n. 11.445/2007), que tem estreita relação com processos ocorridos dentro da bacia hidrográfica.

No âmbito do abastecimento de água e do esgotamento sanitário, que são dependentes da disponibilidade hídrica na bacia hidrográfica para atender à demanda urbana de água, para retira de água seja para abastecimento seja para lançamento dos efluentes gerados na cidade.

Na drenagem urbana, na preservação dos cursos de água no ambiente urbano, processo este dependente da regulação do uso do solo urbano. E a gestão dos resíduos sólidos que pode gerar significativos impactos na qualidade da água dos corpos hídricos.

\section{Política de saneamento}

Em 1968, com a intensificação do processo de urbanização brasileiro, iniciou-se a organização dos serviços de saneamento básico no Brasil com o advento do Planasa (Plano Nacional de Saneamento).

O Planasa teve como principal objetivo a construção de sistemas de abastecimento de água e esgotamento sanitário e desenvolvimento industrial do País. Naquele momento, as atenções foram voltadas para a regionalização dos serviços no âmbito de cada estado, criando companhias estaduais de saneamento, modelo adotado por boa parte dos municípios brasileiros.

Durante o período de atuação do Planasa, os serviços e a cobertura do saneamento no Brasil foram ampliados. No entanto, essa ampliação aconteceu de forma desigual em dois sentidos: 1) os investimentos foram principalmente para o abastecimento de água, deixando o esgotamento sanitário em segundo plano; e 2) foram priorizadas as áreas com as principais plataformas de desenvolvimento industrial.

Após a extinção do Planasa, com o cenário de instabilidade política e econômica do País, aliado à fragilidade institucional do período (década de 1980), houve uma significativa queda na qualidade dos serviços de saneamento no Brasil.

Entretanto, com a publicação da Constituição Federal de 1988, o saneamento ganha espaço, e é atribuída ao município a titularidade dos serviços de saneamento e, consequentemente, a responsabilidade pela formulação de uma política municipal de saneamento básico.

Em 2007, com a aprovação da lei n. 11.445 - Política Federal de Saneamento Básico, que trata das diretrizes nacionais para o saneamento básico, o País passou a contar com um novo marco legal para o setor de saneamento, após quase duas décadas de uma lacuna político-institucional.

$\mathrm{Na}$ estrutura institucional do saneamento no Brasil (Figura 4), mesmo em nível de município, é percebida uma estrutura fragmentada, ou seja, a política municipal não tem ainda um arranjo articulado. Como pode ser observado na Figura 4, embora não exista um sistema nacional de saneamento, as estruturas institucionais dos órgãos responsáveis pelo saneamento estão instituídas.

A secretaria nacional de saneamento ambiental está inserida na estrutura do 
ministério das cidades (Figura 3 e 4). No âmbito dos estados e municípios, sua estrutura é composta por conselhos estaduais e municipais de saneamento, secretarias executivas de saneamento e agências reguladoras da prestação dos serviços de saneamento.

Os órgãos colegiados, no âmbito da política de saneamento, têm função consultiva e, de acordo com o artigo 47, da Lei de Saneamento, não existe obrigatoriedade, tornando a sua existência facultativa em todos os níveis. Em nível nacional, estadual e municipal existem câmaras e comitê técnico inseridos dentro dos conselhos das cidades que tratam dos assuntos de saneamento.

Entre os anos de 2017 e 2018, houve uma discussão interessante no Brasil sobre a regulação dos serviços de saneamento. O Ministério das Cidades convocou alguns órgãos relacionados ao saneamento para discutir a proposta de incluir a regulação do saneamento nas atribuições da Agência Nacional de Águas (ANA - agência executiva dos recursos hídricos no Brasil).

É importante destacar a complexidade de um mesmo órgão, no caso a ANA, possuir os papéis de usuária e fiscalizadora do mesmo bem. $E$, ainda, de a mesma agência regular serviços (no caso do saneamento) e recursos (no caso dos recursos hídricos).

\section{Articulação das políticas públicas no Brasil: avanços e entraves}

Em termos de políticas públicas, sobretudo no tocante a política urbana e ambiental, o Brasil possui um avançado arcabouço legal, no entanto ainda existe uma considerável lacuna nas ações de planejamento e gestão

Figura 4 - Estrutura institucional do saneamento no Brasil

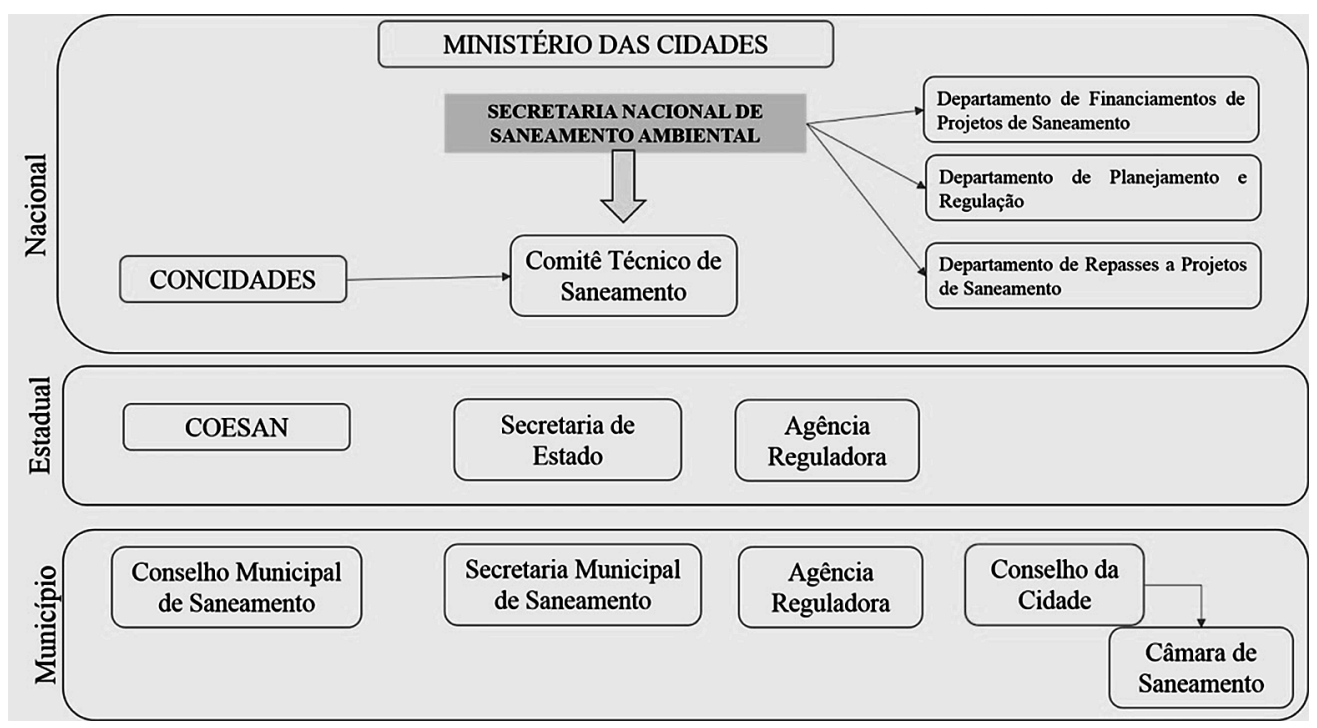

Fonte: elaborado a partir de Brasil (2017). 
(Alvim, Kato e Rosin, 2015), tanto nas questões ambientais quanto na percepção das dinâmicas urbanas.

No caso das políticas de recursos hídricos e da política urbana, por exemplo, os planos de bacia e de recursos hídricos, plano municipal de saneamento básico e os planos diretores municipais são planos de ações para seus respectivos setores que são produzidos independentes um do outro, tanto no conteúdo quanto no período de elaboração, mesmo tento forte dependência.

Na Figura 5, é possível notar a relação de dependência entre o saneamento e a gestão dos recursos hídricos. A política de saneamento é parte da política urbana, embora tenha legislação própria, mas suas atividades são completamente dependentes das decisões e definições ocorridas na bacia hidrográfica, que está no âmbito da política de recursos hídricos.

Outra questão importante no âmbito da política urbana e de recursos hídricos são as responsabilidades definidas para os atores envolvidos. Na política de recursos hídricos, o município é visto com um simples representante do poder público no comitê de bacia, embora ele seja parte do território da bacia hidrográfica.

Embora o município não seja protagonista no sistema de gestão de recursos

Figura 5 - A política de saneamento e suas inter-relações com a política urbana e de recursos hídricos

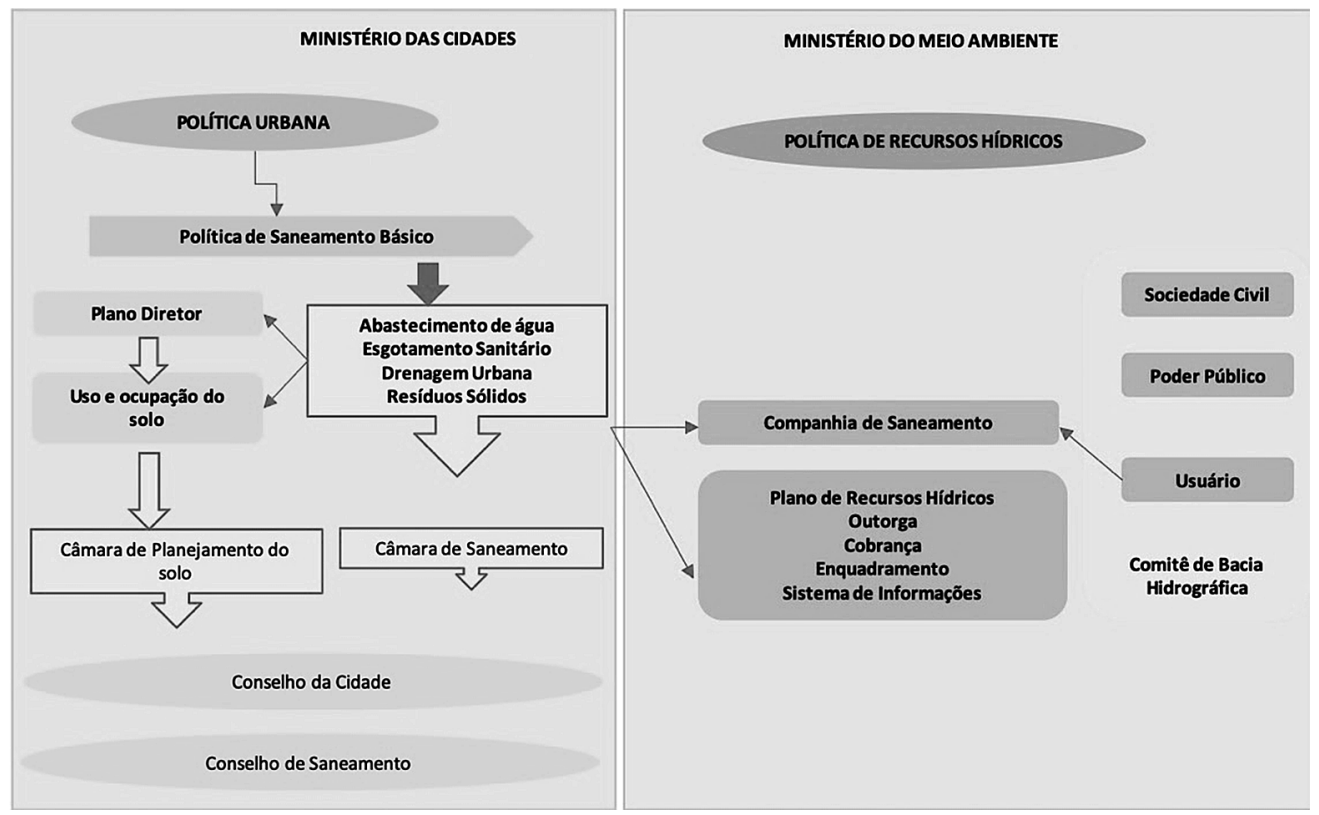

Fonte: elaborado pela autora, em 2019. 
hídricos ele poderá ter representação da gestão do comitê de bacia hidrográfica. Assim, dada a dificuldade de avanços na gestão de recursos hídricos sem avanços no saneamento, a não incorporação do município como ente protagonista no sistema de gestão de recursos hídricos, especialmente para discutir as questões relacionadas ao saneamento básico, torna-se um fator limitante para uma gestão integrada.

Além da falta de integração entre os entes federativos, outros problemas são a falta de articulação institucional e dos instrumentos de gestão (Quadro 1) assim como a incompatibilidade temporal entre planos e períodos da administração pública (Philippi Jr, Marcon e Grisotto, 2009). Na Figura 6, é possível observar a construção histórica de aprovação das legislações no âmbito das gestões de recursos hídricos e urbana no Brasil e seus "desencontros temporais".

No Quadro 1, são apresentados os instrumentos das políticas de recursos hídricos, saneamento e do estatuto da cidade. Nele, é possível perceber, também, uma lacuna, como por exemplo, no planejamento. Os planos de bacia hidrográfica (gestão de recursos hídricos), planos diretores municipais e planos municipais de saneamento básico (gestão urbana) são construídos independentemente, sem a participação de atores das três gestões. No entanto, o planejamento do solo influencia os serviços de saneamento, que influenciam os recursos hídricos da bacia hidrográfica, pois se há uma fragmentação na estrutura institucional existe também uma dependência física desses processos.

Figura 6 - Linha do tempo das legislações das gestões de recursos hídricos e urbana no Brasil

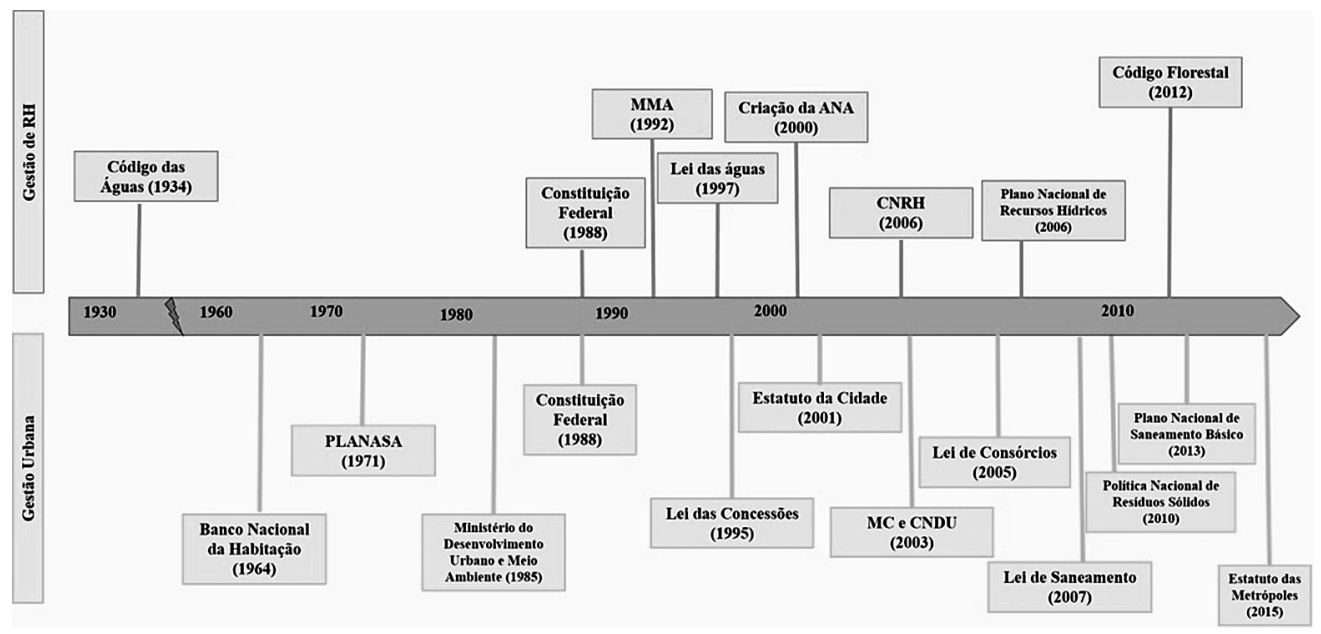

Fonte: elaborado pela autora, em 2019. 
Quadro 1 - Instrumentos das políticas de recursos hídricos, urbana e saneamento

\begin{tabular}{|l|l|l|}
\hline \multicolumn{1}{|c|}{$\begin{array}{c}\text { Política de Recursos Hídricos } \\
\text { (Lei 9.433/1997) }\end{array}$} & \multicolumn{1}{|c|}{$\begin{array}{c}\text { Política Urbana } \\
\text { (Lei 10.257/2001) }\end{array}$} & \multicolumn{1}{|c|}{$\begin{array}{c}\text { Política de Saneamento } \\
\text { (Lei 11.445/2007) }\end{array}$} \\
\hline Planos de recursos hídricos & Planejamento municipal ${ }^{1}$ & Planejamento \\
\hline $\begin{array}{l}\text { Cobrança pelo uso de recursos } \\
\text { hídricos }\end{array}$ & Institutos tributários e financeiros ${ }^{2}$ & Regulação \\
\hline $\begin{array}{l}\text { Outorga dos direitos de uso dos } \\
\text { recursos hídricos }\end{array}$ & Institutos jurídicos e políticos ${ }^{3}$ & Fiscalização \\
\hline $\begin{array}{l}\text { Enquadramento de corpos d'água } \\
\text { em classes segundo os usos } \\
\text { preponderantes }\end{array}$ & $\begin{array}{l}\text { Estudo prévio de impacto ambiental } \\
\text { (ElA) e estudo prévio de impacto de } \\
\text { vizinhança (EIV) }\end{array}$ & Prestação dos serviços \\
\hline $\begin{array}{l}\text { Sistema de informações sobre } \\
\text { recursos hídricos }\end{array}$ & & $\begin{array}{l}\text { Sistema Nacional de Informações } \\
\text { sobre Saneamento }\end{array}$ \\
\hline
\end{tabular}

Fonte: elaborado a partir da Lei das Águas, do Estatuto da Cidade e da Lei de Saneamento.

É notado também que, dentro de um mesmo ente federado (Philippi Jr, Marcon e Grisotto, 2009) e até mesmo ministério, exista uma a fraca coordenação entre as políticas existentes que não se articulam, como o ministério do meio ambiente, responsável pelas política de recursos hídricos e política de meio ambiente, e suas ações são setorizadas e independentes.

\section{Articulação das políticas públicas no Brasil: possibilidades de integração}

A política nacional de recursos hídricos alcançou importantes progressos no Brasil, no entanto, a reforma do setor de recursos hídricos ainda não colheu plenamente os benefícios econômicos, sociais e ambientais esperados (OECD, 2015).

Uma das principais lacunas que dificultam a implementação efetiva da gestão dos recursos hídricos é a dificuldade de formular e implementar essas políticas pelos diferentes níveis administrativos e territoriais.

Uma alternativa para esse problema é a definição de competências no âmbito das políticas públicas que, por meio de regras legais, pode obrigar os atores a compartiIhar decisões e tarefas (Abrucio, 2005). A definição de competências e tarefas compartilhadas é necessária no caso da gestão urbana e dos recursos hídricos, com foco especial na atuação transescalar ${ }^{4}$ por parte dos atores envolvidos.

A governança também é um elemento importante na articulação de políticas (Schulz et al., 2016), pois envolve questões significativas como: conflitos de valores entre diferentes partes interessadas ou atores envolvidos.

Mas, da mesma forma que decisões e ações tomadas em outros âmbitos criam uma série de externalidades que pode gerar problemas para outros atores envolvidos no sistema de governança, a governança da 
água afeta e é igualmente afetada por processos de decisão de outras áreas (Daniell e Barreteau, 2014), entre elas, as políticas de uso do solo e a gestão ambiental.

Assim, a governança no contexto do território torna-se uma importante ferramenta quando se têm como principais desafios a necessidade de articulação de gestões e integração de políticas setoriais e conflitos de competências e escalas, assim como interesses difusos de atores envolvidos no processo.

Como, por exemplo, quando se observa o contexto municipal associado a bacia hidrográfica, em que as atividades desenvolvidas na cidade geram impactos na bacia hidrográfica, e esses impactos são refletidos novamente na cidade, sejam os efeitos positivos e negativos dos processos ocorridos na bacia hidrográfica.

Nessa perspectiva, a política de saneamento poderá ser um ponto de articulação entre a gestão da política urbana e de recursos hídricos como um campo interessante para a atuação transescalar dos atores envolvidos.

Embora no artigo 4 da Política Federal de Saneamento Básico seja dito que "os recursos hídricos não integram os serviços públicos de saneamento básico", a mesma lei traz como princípio a "integração das infraestruturas e serviços com a gestão eficiente dos recursos hídricos" e a "adoção de medidas de fomento à moderação do consumo de água". Os dois princípios citados reforçam a necessidade de uma gestão integrada, visto que não fazem parte da mesma política, mas apresentam uma forte dependência entre a gestão dos recursos hídricos e a adequada prestação dos serviços de saneamento básico.
Dessa forma, é notado que, mesmo os recursos hídricos não integrando os serviços de saneamento, eles são diretamente afetados por tais serviços e devem estar articulados com o planejamento do solo urbano e a gestão dos recursos hídricos na bacia hidrográfica.

A articulação das instituições que fazem parte das políticas urbana, de saneamento e de recursos hídricos, é percebida como uma estratégia para promover a boa governança e a responsabilidade na tomada de decisão e na adoção de medidas que minimizem as pressões urbanas diante da disponibilidade de água na bacia hidrográfica.

No nível de planejamento e gestão urbana, a cidade é cenário de diversas pressões urbanas sobre o ambiente, como exemplo o uso e ocupação do solo e consumo hídrico, que envolvem diferentes atores, em diversas escalas e interesses.

Na Figura 7, é apresentada uma proposta de articulação dos entes das políticas de recursos hídricos, urbana e de saneamento, considerando a atuação transescalar dos atores envolvidos e as interdependências dos processos e das decisões no âmbito de cada política.

A proposta de articulação destaca a aproximação dos atores envolvidos através dos espaços participativos, nos quais tanto o poder público - principal tomador de decisão - quanto a sociedade se apropriam das questões inerentes à gestão.

Assim, na proposta preliminar apresentada, a participação dos atores envolvidos no processo de gestão, seja ela no âmbito da política urbana, dos recursos hídricos ou do saneamento, necessita ser transversal. Como no caso da companhia de 
Figura 7 - Proposta de articulação dos entes das políticas de recursos hídricos, urbana e de saneamento

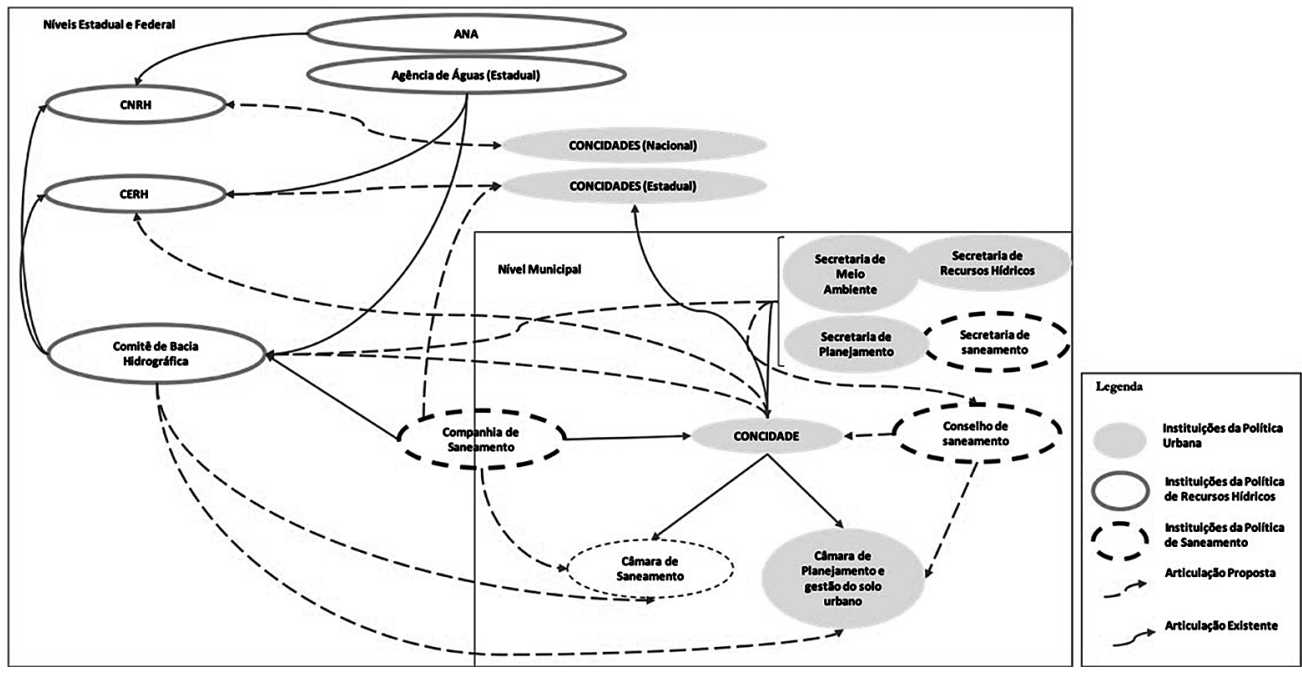

Fonte: elaborado pela autora, em 2019.

abastecimento de água, que atua no saneamento e tem assento no Comitê de Bacia Hidrográfica e no Conselho da Cidade, podendo, assim, proporcionar um debate robusto sobre as necessidades e os impactos das decisões nas cidades e na bacia hidrográfica.

Destaca-se que este artigo é parte de uma tese de doutorado, sendo assim, a proposta apresentada na Figura 7 é o primeiro resultado da pesquisa, na qual serão investigadas outras questões relacionadas à integração das gestões como: em que aspectos a governança dos recursos hídricos, através de suas políticas, planos e espaços de participação, deverá interagir com a gestão do espaço urbano e o território municipal para proporcionar uma adequada governança dos recursos hídricos? Como gerar estratégias para atender aos requisitos dessa governança?

No âmbito dessas questões, a pesquisa toma por base o pressuposto de que a efetiva integração das gestões urbanas e dos recursos hídricos é um caminho para superar os desafios associados à boa governança dos recursos hídricos, partindo da ideia de que o município é um ator fundamental no processo. 


\section{Conclusões}

Diante da grande pressão sobre os recursos hídricos, gerados pela dinâmica do processo de urbanização, é necessária uma adequada integração e a gestão da água e o planejamento do uso do solo para reduzir o volume do impacto nos recursos hídricos.

Embora uso e ocupação do solo e os recursos hídricos ainda não sejam compreendidos como elementos do mesmo espaço, as ações desenvolvidas no âmbito de uma política têm potencial de influenciar setores da outra política.

No Brasil, existe um avançado arcabouço legal, como a Política Nacional de Recursos Hídricos, no entanto, ainda existem consideráveis lacunas nas ações de planejamento e gestão, como o espaço reduzido que o município possui no sistema de gestão das águas.

Nessa perspectiva, vislumbra-se a política de saneamento como um possível ponto de articulação entre a gestão da política urbana e de recursos hídricos e um campo interessante para a atuação transescalar dos atores envolvidos. Apesar de o saneamento ser de competência municipal, ele influencia e depende dos processos ocorridos dentro da bacia hidrográfica.

Então, diante da interdependência dos processos e das decisões no âmbito de cada política sugere-se a articulação dos atores envolvidos através dos espaços participativos, tornando a participação do município efetiva nos processos de tomada de decisão na gestão dos recursos hídricos.

O esquema proposto na Figura 7 objetiva preencher as lacunas entre os níveis administrativos federal, estadual e municipal, a fim de melhor alcançar uma integração adequada entre os setores das políticas de recursos hídricas, urbanas e de saneamento no Brasil.

É importante destacar que, no sentido de articular as escalas apropriadas aos desafios da gestão dos recursos hídricos, é necessária uma definição mais clara nas políticas das questões de articulação do território municipal com a escala de bacia hidrográfica. $\mathrm{O}$ envolvimento dos atores de diferentes escalas nos espaços de participação (comitê de bacia, conselho da cidade, câmara de saneamento, entre outros) torna-se fundamental, à medida que promove o diálogo e o consenso entre as demandas e disponibilidades relacionadas aos recursos hídricos, questões fundamentais para uma efetiva gestão desses recursos.

Apesar de o poder público municipal ter assento nos comitês de bacia hidrográfica, a participação desse ator sobre a gestão das águas é indireta e pequena ante a responsabilidade e os impactos incidentes na bacia hidrográfica em que ele está inserido. Diante desse fato, o reconhecimento do município como ente fundamental na gestão dos recursos hídricos e o fortalecimento da representação municipal nos espaços participativos possibilitariam que os problemas relacionados aos recursos hídricos nos municípios fossem bem discutidos e, por consequência, houvesse a definição de ações no sentido de resolver tais questões.

Cabe destacar, ainda, que o presente trabalho foi realizado considerando a conjuntura político-administrativa anterior 
a janeiro de 2019, período em que houve uma considerável alteração na organização do ministério do meio ambiente assim como das instituições e espaços participativos no âmbito das políticas analisadas, e a extinção do ministério das cidades.

\section{[I] https://orcid.org/0000-0002-1915-4638}

Instituto Federal de Educação, Ciência e Tecnologia da Paraíba, Curso de Edificações. Picuí, PB/Brasil.

esterluiz.eng@gmail.com

\section{[II] https://orcid.org/0000-0002-3446-6752}

Universidade Federal de Campina Grande, Departamento de Engenharia Civil. Campina Grande, PB/Brasil.

mm-ribeiro@uol.com.br

\section{[III] https://orcid.org/0000-0003-3741-4736}

Universidade Federal de Campina Grande, Departamento de Engenharia Civil. Campina Grande, PB/Brasil.

liviabmiranda@gmail.com

\section{Notas}

(1) Plano diretor, disciplina do parcelamento, do uso e da ocupação do solo, zoneamento ambiental, plano plurianual, diretrizes orçamentárias e orçamento anual, gestão orçamentária participativa, planos, programas e projetos setoriais e planos de desenvolvimento econômico e social.

(2) Imposto sobre a propriedade predial e territorial urbana - IPTU, Contribuição de melhoria e Incentivos e benefícios fiscais e financeiros.

(3) Desapropriação, servidão administrativa, limitações administrativas, tombamento de imóveis ou de mobiliário urbano, instituição de unidades de conservação, instituição de zonas especiais de interesse social, concessão de direito real de uso, concessão de uso especial para fins de moradia, parcelamento, edificação ou utilização compulsórios, usucapião especial de imóvel urbano, direito de superfície, direito de preempção, outorga onerosa do direito de construir e de alteração de uso, transferência do direito de construir, operações urbanas consorciadas, regularização fundiária, assistência técnica e jurídica gratuita para as comunidades e grupos sociais menos favorecidos, referendo popular e plebiscito e legitimação de posse.

(4) Termo utilizado por Vainer (2006) em seu trabalho intitulado “Lugar, região, nação, mundo: explorações históricas do debate acerca das escalas de ação política". 


\section{Referências}

ABRUCIO, F. L. (2005). A coordenação federativa no Brasil: a experiência do período FHC e os desafios do governo Lula. Revista de Sociologia e Política. Curitiba, v. 24, pp. 41-67.

ALVES, J. A. (2018). Turismo, recursos de uso comum e conflitos socioambientais em Pipa - Tibau do Sul/RN: Uma perspectiva à luz dos princípios de Ostrom. Tese de doutorado. Campina Grande, Universidade Federal de Campina Grande.

ALVIM, A. T. B.; KATO, V. R. C. e ROSIN, J. R. de G. (2015). A urgência das águas: intervenções urbanas em áreas de mananciais. Cadernos Metrópole. São Paulo, v. 17, n. 33, pp. 83-107.

BARRON, N. J.; KULLER, M.; YASMIN, Y.; CASTONGUAY, A. C.; CONN, R. J.; COPA, V.; DUNCAN-HORNER, E.; GIMELLI, F. M.; JAMALI, B.; NIELSEN, J. S.; NOVALIA, K. N.; SHEN, P. F.; BROWN, R. R. e DELETIC, A. (2017). Towards Water Sensitive Cities in Asia: An Interdisciplinary Journey. Water Science and Technology. v. 76, n. 4. wst2017287; DOI: 10.2166/wst.2017.287.

BRASIL (1997). Lei n. 9.433, de 8 de janeiro de 1997. Institui a Política Nacional de Recursos hídricos, cria o Sistema Nacional de Gerenciamento de Recursos hídricos. Brasília, DF.

(2017). Ministério do Meio Ambiente. Disponível em: www.mma.gov.br.

BROWNE, G. R. e RUTHERFURD, I. D. (2017). The Case for "Environment in All Policies": Lessons from the "Health in All Policies" Approach in Public Health. Environmental Health Perspectives, v. 125, n. 2, pp. 149-154. DOI: http://dx.doi.org/10.1289/EHP294.

CAMPOS, V. N de O. e FRACALANZA, A. P. (2010). Governança das Águas no Brasil: Conflitos pela Apropriação da Água e a Busca da Integração como Consenso. Ambiente \& Sociedade. São Paulo, v. XIII, n. 2, pp. 365-382.

CARVALHO, C. O. e MORAES, A. F. A. (2016). Políticas públicas e movimentos sociais no planejamento e gestão urbanos brasileiros. Panóptica, v. 11, n. 2, pp. 571-605.

DANIELL, K. A. e BARRETEAU, O. (2014). Water governance across completing scales: Coupling land and water management. Journal of Hydrology, v. 519, pp. 2367-2380. DOI: https://doi.org/10.1016/j. jhydrol.2014.10.055.

FERREIRA, M. I. P.; SILVA, J. A. F. da e PINHEIRO, M. R. de C. (2008). Políticas Públicas e gerenciamento de recursos hídricos. Boletim do Observatório Ambiental Alberto Ribeiro Lamego. Campos dos Goytacazes, v. 2, n. 2, pp. 133-167. DOI: https://doi.org/10.19180/2177-4560.20080013

KNIEPER, C.; HOLTZ, G.; KASTENS, B. e PAHL-WOSTL, C. (2010). Analysing water governance in heterogeneous case studies - Experiences with a database approach. Environmental science \& policy, v. 13, pp. 592-603.

LOTTA, G. e FAVARETO, A. (2016). Desafios da integração nos novos arranjos institucionais de políticas públicas no Brasil. Revista de Sociologia e Política. Curitiba, v. 24, n. 57, pp. 49-65.

MITCHELL, D.; ENEMARKB, S. T. e VAN DER MOLEN, P. (2015). Climate resilient urban development: Why responsible land governance is important. Land Use Policy, v. 48, pp. 190-198. DOI: 10.1016/j. landusepol.2015.05.026.

MONTE-MÓR, R. L. de M. (2007). Planejamento Urbano no Brasil: emergência e consolidação. Revista Eletrônica de Ciências Humanas e Sociais, v. 1, n. 1, pp. 71-96. 
MURTHA, N. A.; CASTRO, J. E. e HELLER, L. (2015). Uma perspectiva histórica das primeiras políticas públicas de saneamento e de recursos hídricos no Brasil. Ambiente \& Sociedade. São Paulo, v. XVIII, n. 3, pp. 193-210.

NÓBREGA, R. L. B.; GALVÃO, C. de O.; PALMIER, L. R. e CEBALLOS, B. S. O. de (2012). Aspectos políticoinstitucionais do aproveitamento de água de chuva em áreas rurais do semiárido brasileiro. Revista Brasileira de Recursos Hídricos. Porto Alegre, v. 17, n. 4, pp. 109-124.

OECD (2015). Governança dos recursos hídricos no Brasil. Paris, OECD Publishing.

PEIXOTO, F. da S.; STUDART, T. M. de C. e CAMPOS, J. N. B. (2016). Gestão das águas urbanas: questões e integração entre legislações pertinentes. Revista de Gestão de Água da América Latina. Porto Alegre, v. 13, n. 2, pp. 160-174.

PERES, R. B. e SILVA, R. S. (2013). Interfaces da gestão ambiental urbana e gestão regional: análise da relação entre Planos Diretores Municipais e Planos de Bacia Hidrográfica. Urbe. Revista Brasileira de Gestão Urbana. v. 5, n. 2, pp. 13-25.

PHILIPPI JR, A.; MARCON, G. e GRISOTTO, L. E. G. (2009). Desafios para a gestão de recursos hídricos e o desenvolvimento urbano. Revista de Gestão de Água da América Latina. Porto Alegre, v. 6, n. 2, pp. 65-91.

RUNHAAR, H.; DRIESSEN, P. e UITTENBROEK, C. (2014). Towards a systematic framework for the analysis of environmental policy integration. Environmental Policy and Governance, v. 24, n. 4, pp. 233-246.

SCHULZ, C. et al. (2017). The value base of water governance: a multi-disciplinary perspective. Ecological Economic, v. 131, n. C, pp. 241-249.

SERRAO-NEUMANN, S.; RENOUF, M.; KENWAY, S. J. e LOW CHOY, D. (2017). Connecting land-use and water planning: prospects for an urban water metabolism approach. Cities. v. 60, pp. 13-27.

SOUZA, C. (2006). Políticas Públicas: uma revisão de literatura. Sociologias. Porto Alegre, n. 16, pp. 20-45.

TONELLA, C. (2013). Políticas Urbanas no Brasil: marcos legais, sujeitos e instituições. Revista Sociedade e Estado, v. 28, n. 1, pp. 29-52.

VAINER, C. B. (2006). Lugar, região, nação, mundo: explorações históricas do debate acerca das escalas de ação política. Revista Brasileira de Estudos Urbanos e Regionais, v. 8, n. 2, pp. 9-29.

VEIGA, L. B. E. e MAGRINI, A. (2013). The brazilian water resources management policy: fifteen years of success and challenges. Water Resources Management, v. 27, n. 7, pp. 2287-2302.

WONG, T. H. F. (2017). Water sensitive urban design - the journey thus far. Australasian Journal of Water Resources, v. 10, n. 3, pp. 213-222.

Texto recebido em $18 /$ jul/2019

Texto aprovado em 21/jan/2020 
ERRATA - http://dx.doi.org/10.1590-2236-9996-2020v22n48

Cadernos Metrópole, v. 22, n. 48, 2020

No artigo "Integração de políticas públicas no Brasil: o caso dos setores de recursos hídricos, urbano e saneamento"

DOI: http://dx.doi.org/10.1590/2236-9996.2020-4804

Onde se lia na página 417:

Ester Luiz de Araújo Grangeiro [l]

Leia-se:

Ester Luiz de Araújo Grangeiro [I]

Márcia Maria Rios Pinheiro [II]

Lívia Izabel Bezerra de Miranda [III]

\section{Onde se lia na página 432 :}

[l] https://orcid.org/0000-0002-1915-4638

Instituto Federal de Educação, Ciência e Tecnologia da Paraíba, Curso de Edificações. Picuí, PB/Brasil. esterluiz.eng@gmail.com

\section{Leia-se:}

[l] https://orcid.org/0000-0002-1915-4638

Instituto Federal de Educação, Ciência e Tecnologia da Paraíba, Curso de Edificações. Picuí, PB/Brasil.

esterluiz.eng@gmail.com

\section{[II] https://orcid.org/0000-0002-3446-6752}

Universidade Federal de Campina Grande, Departamento de Engenharia Civil. Campina Grande, PB/Brasil. mm-ribeiro@uol.com.br

\section{[III] https://orcid.org/0000-0003-3741-4736}

Universidade Federal de Campina Grande, Departamento de Engenharia Civil. Campina Grande, PB/Brasil. liviabmiranda@gmail.com 
ERRATA - http://dx.doi.org/10.1590-2236-9996-2020v22n48 4804

Cadernos Metrópole, v. 22, n. 48, 2020

No artigo "Integração de políticas públicas no Brasil: o caso dos setores de recursos hídricos, urbano e saneamento"

DOI: $h$ ttp://dx.doi.org/10.1590/2236-9996.2020-4804

Onde se lia na página 417:

Ester Luiz de Araújo Grangeiro [l]

Márcia Maria Rios Pinheiro [II]

Lívia Izabel Bezerra de Miranda [III]

\section{Leia-se:}

Ester Luiz de Araújo Grangeiro [l]

Márcia Maria Rios Ribeiro [II]

Lívia Izabel Bezerra de Miranda [III] 